\title{
Efficiency Analysis of Crop Production in Gurage Zone: The Case of Abeshige Woreda, Snnpr Ethiopia
}

\author{
Hayatu Mude Sherif
}

Department of Economics, Wolkite University, Wolkite, Ethiopia

\begin{abstract}
Efficiency is an accomplishment through operation to use least amounts of inputs to achieving a highest level of output it is an important area of study because ensuring efficiency minimizes the wastage of resources while accomplishing the desired outputs. This study was to decide the economic efficiency of crop producing rural farmers in abeshigeworeda or district which is one of the districts in gurage zone, SNNPR. Six kebeles and 399 sample respondents were selected through applying stratify sampling procedure. The descriptive statics, Parametric Stochastic Frontier Production Function, the Cobb Douglas production function and Tobit regression methods were used to accomplish the objective of the study. The rural farmers ranked constraints were analyzed through using Kendall's coefficient of concordance to test for the degree of agreement in ranking. Technical efficiency estimates range from 19.94 percent to 95.16 percent with a mean efficiency of 64.69 percent, while Allocative efficiency estimates range from 15.52 percent to 97.69 percent with a mean of 57.47 percent. The economic efficiency estimates range from 10.9 percent to 81.29 percent with a mean of percent. As the result indicated, crop output was positively and significantly influenced by labor, seed, fertilizer, house hold size and land size. This study therefore recommended that would improve the application of full packages of fertilizer and improved seed, appropriate use of productive labors, line method of seeding and membership of individual farmers.
\end{abstract}

Keywords-Allocative, Economic, Cobb Douglas, Technical, Tobit and efficiency.

\section{INTRODUCTION}

1.1 background of the study

There are two basic pressures that enforcing nations, specially developing countries like Ethiopia, in order to increase agricultural production and productivity while the first one is the food security challenges that is demanded to feed the existing population size of the nations. The other force is the demand of producing surplus products to supply to domestic and also to international markets thereby able to earn foreign currency. Ethiopia had designed and implemented agricultural development policy and strategies in 2003 to respond about those basic challenging pressures which is broadly incorporated ensuring of food security and accelerated economic growth through enhancing of farmers market oriented production system. More over the policy document focused up on the subsistent characteristics of the farms and small scale producers which are the majority of agricultural products have supplied (Alemayehu et al, 2011).
As components of growth, export has been one of the strategic area of the country despite a great gap has been observed between the import and export commodity values of the country. According to CIA 2017, the annual export value of the country was 4.14 billion USD whereas the total import commodity value was 12.08 USD as a result the trade deficit of the country was negative $31 \%$ by the year 2016. Ethiopia mainly exports agricultural outputs and imports some sophisticated industrial commodities. The country's production and productivity of the agricultural sector improves in some extent and the overall real economic growth of the country by the year 2017 was around $8.5 \%$, though, it has facing troubles due to low volume and value of export products to foreign trades, the availability of food insecurity which is not balanced with the current population pressure i.e. 99.47 million with the average growth rate of $2.89 \%$ per year (CIA world fact book, 2018).

In Ethiopia, Pulses are one of agricultural crop grown on 12.4 percent of the total area cultivated, by a total of 6.8 
million farmers. Together, these holders produce a yearly average of 1.5 million ton of pulses, which is 8.5 percent of total crop production (Alemayehu et al, 2011). Producing crops has a number of advantages to ensure the food security and economic demands of a producer because it allows for double cropping in a season using early maturing cultivars and it serves for consumption and as a source of cash to farmers. Moreover to this, it contributes towards a balanced diet because of its high protein content and convenient for intercropping because of its short growth duration and diversegrowth habit. It serves as an export commodity to earn foreign currency (walelign: 2015).

\subsection{Statement of the problem}

The global efficiency level is very low when it compared to the expected potential productivity level and hence the attained average yield of the crop so far in the world is 8 $\mathrm{qt} / \mathrm{ha}$ (walelign, 2015). The presence of such low level of production efficiency at global level is as a result of production efficiency differences between regions and nations of the world. As many of literatures indicated, the efficiency level of crop production is determined by a number of factors of production and their effect is also different from place to place. Some regions like the developed world has a better skills, knowledge, policies, institutional capacity and application of technologies that can lead them to achieve the maximum and potential productivity level of crop whereas countries in the developing world have shown very low production efficiency performance.

The average productivity of the crop in Ethiopia and for SNNPR is recorded as $12.6 \mathrm{qt} / \mathrm{ha}$ and $11.46 \mathrm{qt} / \mathrm{ha}$ respectively (ibid). This implies that as there is a great potential to increase productivity and production of the crop. Improving the crop's productivity and production within Ethiopia should be intensified as a result of its current socio economic and demographic existence that requires equitable source of domestic nutritional food supply, the presence of higher demands for foreign imported products with low capacity of exportable products that has brought unbalanced trade problem and this in turn resulted a great shortage of foreign currency within the country. In other speaking as primary sources of all demands of the country, currently agricultural production and productivity is not proportionate with the total population demands and the targeted economic growth rate to be achieved(Essa: 2011).

According to Ageteet al. (2014), Ethiopia is the top twelve producers of total legumes in the world generally, the current national average productivity of the crop is $14.8 \mathrm{qt}$ per hectare whereas the average research demonstrated productivity potential is 34 qt per hectare in the country (Mulugeta et al., 2015). This implies that as there is a great yield differences within the two fields, even the nationally attained productivity result is lower than half of the research demonstrated productivity potential and hence it needs a great attention to improve the existing situation.

To address the causes of the yield gap problem, different works of scholars have been conducted though many of them have considered only the evaluation of technical efficiency and allocative part but they were not include economic efficiency measurements of the crop and hence it needs to asses integrated efficiency measurement applications that must include economic efficiency. On the other hand, from the reviewed sample empirical findings of the previous works, it can be to understand that as there are a number of elements in the variable set that can be determine the efficiency level of agricultural production even they have not been exhausted yet by the previous works completely. Moreover, the already conducted works can be considered as bases for this new research to be conducted to check their compliance or variation with the new findings especially for those models of research which are included similar variables. As a result, this study has the objective of to estimate the economic efficiency of rural farmers and also identify the prompting factors that upsetting the existing level of efficiency. Moreover, the study was conducted on crop production, data taking from SNNPR Ethiopia, Gurage zone, Abeshigeworeda or district.

The main objective of the study is to examine the economic efficiency of crop production in SNNPRS, Gurage Zone: AbeshigeWoreda or district, with having the following specific objectives:

I. To assess the level of technical, allocative and economic efficiency of rural farmer crop producers.

II. To analyze the factor affecting technical and economic efficiency of crop production

This research is intended to address the main factors in the process of exported oriented crop production in Gurage zone, Abeshigeworeda or district. Through addressing those limiting factors of production and also quantifying the levels of their impact on technical, allocative and economic efficiencies that provides the relevant inputs to concerned government organizations like agricultural and natural resource bureaus, national level policy makers and other non-governmental organizations who are engaged in agricultural production generally, crop production particularly. 


\section{LITERATURE REVIEWS}

\subsection{Theoretical reviews}

Efficiency and agricultural production

The term efficiency in agricultural production system is a simple way of performance evaluation in the relationship between input conversions towards output. In traditional simple straight forward way of measuring efficiency of a farm could be the achievement of yield per hectare of land. But a given output is a function of multiple in puts in the reality, this is very simplistic way of measurement in that it only considers a single of production (Solomon: 2014).Therefore efficiency measurement in agricultural production is very important to optimize or to get the maximum level of output through using of alternative options or combination of inputs among the multiple ones that can influence the level of out puts. The scope of agricultural production can be expanded and sustained by farmers through efficient use of resources (ESSA 2011: Hailu 2005). For these reasons, efficiency has remained an important subject of empirical investigation particularly in the developing economies where majority of the farmers are resource poor (ESSA, 2011: Umoh, 2006).

\section{Efficiency measurement approaches}

Basically there are two approaches in measurement of efficiency. These are input oriented and output oriented approaches. The former one deals with to answer the questions that by how much input of quantities can be proportionally reduced without changing the output quantity produced. This is an input oriented measure of efficiency. The later one deals with the question as by how much output could be expanded from a given level of inputs. However, both measures will coincide when the technology exhibits constant returns to scale, but are likely to vary otherwise (Coelli and Battese, 2005).

i. Input oriented measurement approaches

In his first work on efficiency, Farrell (1957) illustrated his idea about measuring efficiency with figure, as follow. The SS' is an isoquant, representing technically efficient combinations of inputs, $\mathrm{X}_{1}$ and $\mathrm{X}_{2}$, used in producing output Q. SS' is also known as the best practice production frontier. AA' is an isocost line, which shows all combinations of inputs $X_{1}$ and $X_{2}$ to be used in such a way that the total cost of inputs is equal at all points. However, any firm intending to maximize profits has to produce at Q', which is a point of tangency and representing the least cost combination of $\mathrm{X}_{1}$ and $\mathrm{X}_{2}$ in production of $\mathrm{Q}$. At point $\mathrm{Q}^{\prime}$ the producer is economically efficient.

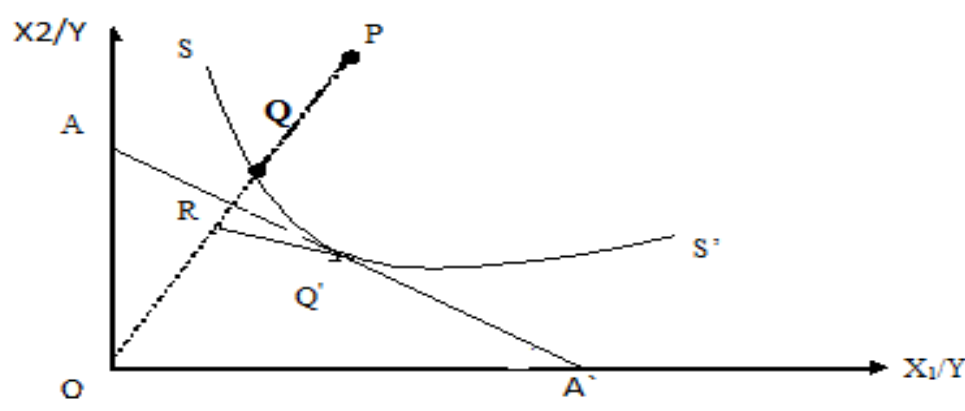

Fig.1: Input oriented measures of technical efficiency; Source: Coelli (1995).

Given figure 1, suppose a farmer is producing his output depicted by isoquant SS' with input combination level of $\left(\mathrm{X}_{1}\right.$ and $\mathrm{X}_{2}$ ). Production at input combination at point $\mathrm{P}$ is not technically efficient because the level of inputs needed to produce the same quantity is $\mathrm{Q}$ on isoquant SS'. In other words, the farmer can produce at any point on SS' with fewer inputs $\left(\mathrm{X}_{1}\right.$ and $\left.\mathrm{X}_{2}\right)$, in this case at $\mathrm{Q}$ in an input-input space. The degree of TE of such a farm is measured as $O Q$ $O P$, which is proportional in all inputs that could theoretically be achieved without reducing the output. Hence all farmers that produce along the isoquant are 100 percent technically efficient (ibid).

\section{ii. Output oriented measurement approaches}

In the output oriented perspective, efficiency is evaluated keeping inputs constant. According to Farrell (1957), output oriented measures can be illustrated by considering the case where production involves two outputs ( $\mathrm{Y}_{1}$ and $\mathrm{Y}_{2}$ ) and a single input (L). If the input quantity is held fixed at a particular level, the technology can be represented by a production possibility curve in two dimensions

\subsection{Empirical Reviews}

Efficiency estimation of crop production

Efficiency measurement is an important and it has a vital role to ensure agricultural production and productivity there by enhancing economic growth of a nation especially for those developing economies whose food energy and source of income majorly relied on agricultural production.

According to Tamiratet al.(2017) conducted a research on Determinants and Resource Use Efficiency of Haricot Bean Production in Halaba Special District, Southern Ethiopia through the application of estimation of production function, and allocative efficiency index (MVP/MFC). The result of this study revealed that haricot bean output was positively and significantly influenced by plot size, amount of fertilizer applied, labor input in man 
days, level of education of the household head, farming experience, frequency of extension contact and types of haricot bean seed used. Resource utilization was found inefficient for the crop in the study area. The result of allocative efficiency index indicated, fertilizer (0.4), pesticide $(0.2)$, labor $(0.5)$ and oxen power $(0.0)$ were over utilized resources.

Essa (2011) determined the economic efficiency of smallholder crops production in the central high lands of Ethiopia. He used a two- limit Tobit regression model results revealed that while family size, farming experience, credit access, walking distance to the nearest main market, and total own land cultivated during the long rainy season affect technical inefficiency positively and significantly; age of household head was found to have a negative and significant influence on technical inefficiency. The results also showed that whereas economic inefficiency was positively and significantly affected by family size, farming experience and membership to associations; for household heads having a role in their community contributed negatively and significantly to economic inefficiency. Moreover the study results also showed that about 37 percent of the farmers in aggregate operate under decreasing returns to scale.

Solomon (2014) estimated and investigated those factors which are affecting technical efficiency of major crops in Ethiopia through using stochastic frontier model. According to this study, land and seed were major determinants of maize production in Ethiopia. Generally, all significant input variables were found to be affect output positively, as it was expected. Moreover, the model output depicted that the mean level of TE for major crops, Teff, Wheat and Maize production was found to be 63.56, 67.26, 84.16 and 91.41 percent, respectively. The inefficiency effect analysis shown that, age of the household head found to be the determinant of technical inefficiency, of teff production. Knowledge about land policy, participation in soil and water conservation activities and education was found to have negative and significant effect on major crops and wheat technical inefficiency ( $1 \%$ significance level). In this study frequency of extension contact, the wealth status of farmers, the fertility status of plots of wheat have affected technical efficiency significantly. Similarly the study investigated flat teff and maize plots are more efficient than otherwise. The other plot specific variable that was found to have negative and significant effect on technical inefficiency of major crop production was adoption of improved seed.

A study that had done by Enderias et al (2013), on productivity and technical efficiency analysis of small ISSN: 2456-1878

https://dx.doi.org/10.22161/ijeab.55.21 holder maize producer in southern Ethiopia, used and applied data envelopment analysis model to determine the levels of technical efficiency and a Tobit regression model to identify factors influencing technical efficiency. Based on this study investigation, productivity of maize was significantly influenced by the use of labor, fertilizer, and oxen power. The study also indicated that the mean technical efficiency was found to be 40 percent indicating that there was substantial level of technical inefficiency of smallholder farmers in maize production. Important factors that significantly affected the technical efficiency were agro-ecology, oxen holding, farm size and use of high yielding maize varieties.

As it cited by Solomon (2014), Geta et al. (2013) undertook a study in SNNPR having the aim to assess the productivity and Technical efficiency of small holder farmers, from 325 randomly selected farmers from Woliyta and Gamgofa zones of SNNPR and hence found that as there was significant level of inefficiency among maize producing farmers. (They used a two stage estimation technique of TE followed by tobit regression model) to identity factors influencing TE. The result showed that production of maize was significant influenced by the use of labor, fertilizer and oxen power. The mean TE was found to be $40 \%$ important factors that significantly affected the TE were agro ecology, oxen holding, farm size, and use of high yielding maize varieties. However, in this study some important farmer's characteristics like age and sex of the house hold heads were not considered in their analysis. The study also conducted on a single and frequently used by previous researches of maize crops. Moreover like majority of previous research works considered only then evaluation of technical efficiency part but not include economic efficiency measurements of the crop.

Generally all the previously conducted research findings indicated that as there are a potential to improve crop productivity or the existence of inefficiency of production at different agro ecology and other existed parameters, thus, it needs to provide a strong emphasis to incorporate those findings in policy and institutional frameworks and also making those influencing determinants of efficiency are favorable for agricultural production. These works can be also considered as a base for new researches to be conducted in the areas of efficiency measurement and use to check their compliance or variation with the new findings especially for those models of research which are included similar variables. On the other hand from the above reviewed samples of empirical findings of the previous works, it can be to understand that as there are a number of elements in the variable set that can determine 
the efficiency level of agricultural production. However, even they have not been exhausted yet by the previous works completely (Essa, 2011). Regarding to the empirical works which have been conducted in Ethiopia depicted that as a number of efficiency based studies have been conducted at different parts of the country though it demands further investigation at different dimension and parameters because in Ethiopia and in other developing countries, agriculture is a dominant elements of their economy and also this agricultural products are sourced from small holder farmers that were produced in a fragmented lands.

ESSA (2011) explained also such kinds of studies are highly relevant to Ethiopia where resources are meager, opportunities for developing and adapting better technology are scarce and with high population pressure that demands equitable sufficient food source. More over to this, agricultural products are the major components of export goods of the country. The other point that should be raised is most of the conducted researches have concentrated on TE of farmers though it needs to asses integrated efficiency measurement applications that must include economic efficiency. As a result this study has the objective to estimate the economic efficiency of rural farmers and also identify the factors affecting the existing level of efficiency. Moreover, the study was conducted on crop production, data taking from Guragezone, Abeshigeworeda or district under SNNPR Ethiopia.

\subsection{Conceptual frame work}

Various levels of exogenous and endogenous factors can determine the level of efficiency in agricultural production process. These production influencing factors can be also categorized basically into socio economic, climatic, and institutional and farm related characteristics

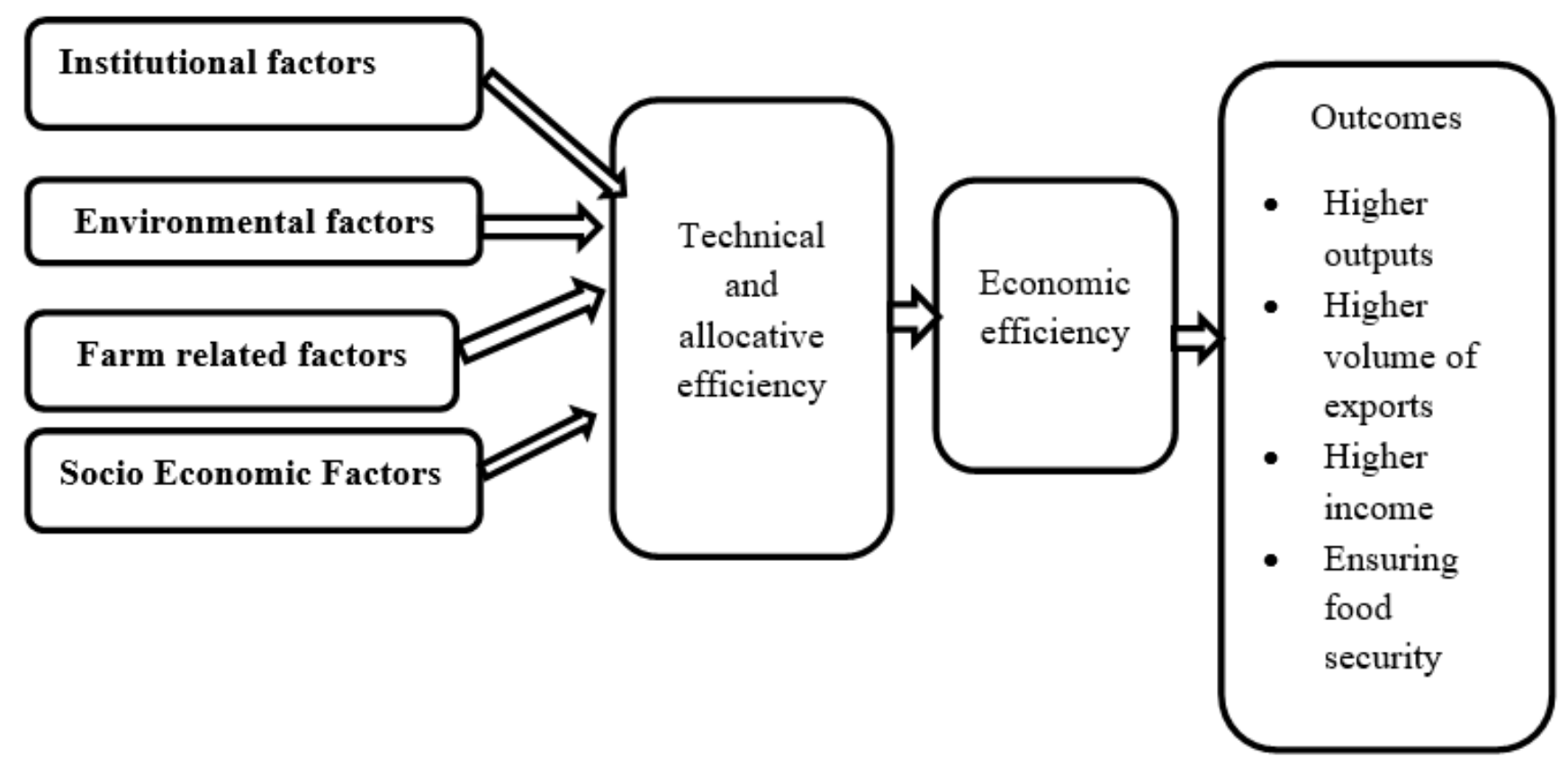

Fig. 2: Source: own conceptualization.

\section{METHODOLOGY OF THE STUDY}

3.1 Method of data collection and sources of data

\subsubsection{Population and sampling techniques}

The total population of this study comprises those farmers who produced crop by the year 2010/2011 spring (locally belg) cropping season at Abeshige districts in gurage zone of southern region. According to the woreda or district's agricultural office information 125650 households were participated in crop production in 2010/2011 spring (locally Belg) season. Therefore the population size of the study was 125650 rural farm house holds from the woreda or district and the targeted interviewers were selected from the population by the application of stratified sampling techniques. Six potential crop producer's kebeles or village had been selected randomly out of the identified producer kebeles or village with under consideration of production potential and the accessibility of rural farms. Randomly selected out of the six potential kebelesor villages as a result 399 representative household samples were selected randomly out of the population of the woreda or district. The total sample size of the study was 
determined based up onDeVaus (2002) formula below here:

$\mathrm{n}=\frac{N}{1+N(a)^{2}} \quad$ Where: $\mathrm{n}=$ sample size, $\mathrm{N}=$ population universe and $a=$ the level of precision

Number of respondents: $\mathrm{n}=\frac{125650}{1+125650(0.05)^{2}}$

$\Longleftrightarrow \mathrm{n}=\frac{125650}{1+125650(0.0025)} \quad \mathrm{p} \Rightarrow \frac{125650}{315.12 .5}=399$

Based on the above procedure the selected kebeles or villages are presented in the next table1.

Table.1: Sample selected Kebeles or villages

\begin{tabular}{|ll|l|c|}
\hline S.n & $\begin{array}{l}\text { Name of selected } \\
\text { kebeles orvillages }\end{array}$ & $\begin{array}{l}\text { Total rural farmers in the } \\
\text { kebeles or villages }\end{array}$ & $\begin{array}{l}\text { Sample rural } \\
\text { frames }\end{array}$ \\
\hline $\mathbf{1}$ & BidoTadale & 825 & 66 \\
$\mathbf{2}$ & Fitejaju & 1050 & 85 \\
$\mathbf{4}$ & borar & 964 & 78 \\
$\mathbf{5}$ & Boketaserite & 585 & 47 \\
6chisanagafersa & 675 & 54 \\
Total & 850 & 69 \\
\hline
\end{tabular}

\subsubsection{Analysis of data}

The data analysis of this study was conducted by using both methods of analysis, namely descriptive statics and parametric (econometric) analysis.

\subsection{Descriptive analysis}

In this method of analysis the descriptive statically technique was applied in order to explain those institutional, socio economic and demographic characteristics of rural crop producers. By using this method of analysis the level of input uses in the production, and related out puts and the distribution of efficiency among rural farmers were presented by using percentages and by a central tendency measurement tools such as mean, frequency, standard deviations.

\subsection{Econometric analysis}

According to Farrel (1957) agricultural production efficiency measurement has three components. These are technical, allocative and economic efficiency components and out of these components, the two (technical and allocative) efficiencies can be computed from production function whereas the economic efficiency of a farm can be computed from the combination of technical and allocative efficiency results.

Technical efficiency of an agricultural production represents the ability of a farm to maximize output for a given set of resource inputs whereas allocative efficiency indicates the extent to which farmers make efficient decisions by using inputs up to the level at which their marginal contribution to production value is equal to the factor cost(Nay, 2012). Among the components of the econometric models, the stochastic frontier production function together with the maximum likelihood measurement approaches are used to estimate the impacts of productive inputs on the outputs of crops production and also Tobit regression model was used to identify the level of economic inefficiencies that are emerged as a result of potential factors affecting in the production processes.

3.3.1 Cobb-Douglas Stochastic frontier production function

According to Battese and Coelli, (1992) The technique assumes that farmers may deviate from the frontier not only due to measurement errors, statically noises or any systematic influencing factors but also because of technical inefficiency. In addition the model allows the estimation of farmers as well as the determinants of technical efficiency simultaneously by the maximum likelihood method

There are two steps of procedures in order to applying this method of analysis. The first one is the impact of productive input use on the output value of crop producers which was determined through the application of the Cobb Douglas production function estimation and through using the ordinary least square method. The second step is the estimation of the TE level of crop producers within the 
study area through applying stochastic frontier production function (SFP) model. As a result Cob-Douglas production function that was fitted with the stochastic frontier models of crop production is as follows:-

$Y i=f(X i, \beta)+\varepsilon i,(1)$

Where $Y_{i}$ is the output of the $j^{\text {th }}$ farm, $X_{i}$ is a vector of inputs, $\beta$ is a vector of unknown parameters, $\varepsilon i=\mathrm{Vi}-\mathrm{Ui}, \mathrm{Vi}$ represents the random error term which is out of the capacity of rural farmers to control, Ui represents the technical inefficiency parts of farm production.

\subsubsection{Empirical models}

\section{Technical Efficiency model specification}

As the production of individual farm assumed to be characterized by Cobb-Douglas production function then the empirical normalized stochastic frontier production function can be specified as indicated below here.

$$
\ln Y_{i}=\beta_{0}+\beta_{1} \ln X_{1 i}+\beta_{2} \ln X_{2 i}+\beta_{3} \ln X_{3 i}+e_{i},
$$

\section{Where}

$\mathrm{Y}_{\mathrm{j}}$ : crop outputs of jthrural farm in $(\mathrm{kg} / \mathrm{ha}), 1 \mathrm{n}$ : denotes the natural logarithm, $\beta$ :Stands for the vector of unknown parameters to be estimated, $\mathrm{X}_{1}$ : is a variable that denotes the amount fertilizer used by the rural farmer in $(\mathrm{kg} / \mathrm{ha})$, $\mathrm{X}_{2}$ : labor (man per day/hectare), $\mathrm{X}_{3}$ : seed amount used in ( $\mathrm{kg} /$ hectare), $j:$ - represents the $\mathrm{j}^{\text {th }}$ observation of the sample, i:- represents the $i^{\text {th }}$ rural farmer within the sample and $e i=\mathrm{Vi}-\mathrm{Ui}$ where $\mathrm{V}_{\mathrm{i}}$ are two sided normally distributed random error

The definition of variables for Cob Douglas Production Function

The lists of variables which are included in the analysis of this study are production amount and seed, labor, fertilizer which are the inputs used for crop production.

Output(Y)is the total quantity of crop produced by each rural farmer household in 2010/2011spring or (locally belg) cropping season. It is measured in $\mathrm{kg}$ per hectare.

Fertilizer $\left(\mathrm{X}_{1}\right)$ it includes NPSB fertilizers which was inorganic and bought and used by producers during spring or (locally belg) season of 2010/2011 production year and measured in kilograms).

Labor $\left(\mathrm{X}_{2}\right)$ considers all labor activities that applied for crop production. It is measured as adult man days perhect are and is the sum of family labor and daily laborer.

$\operatorname{Seed}\left(\mathbf{X}_{3}\right)$ the amount of seed volume that was used by crop producers in 2010/2011 and measured in kilograms.

II. Allocative Efficiency model specification
As of the literature written by chukwuji et al. (2006) indicated the allocative efficiency analysis of agricultural production can be performed by estimating a CobbDougals function through using the ordinary least squares (OLS), followed by computing the value of marginal products (VMP) for each particular factor of production, then after compare it with the marginal input cost (MIC). Using the coefficient estimates from the analysis, the marginal product (MP) of the $\mathrm{i}^{\text {th }}$ factor $\mathrm{X}$ is calculated as

$\mathrm{MP}=\frac{\delta Y}{\partial X}=\beta \frac{Y}{X i}$,

Where, $\mathrm{Y}$ is the geometrical mean of crop yield(mean of natural logarithm),

$\mathrm{X}_{\mathrm{i}}$ is the geometrical mean of inputs, $\beta_{\mathrm{i}}$ is the OLS estimated coefficient of input.

The value of the marginal product of input (MP) can be obtained by multiplying marginal physical product by the price of output $\left(\mathrm{P}_{\mathrm{y}}\right)$.

Thus, allocative efficiency $(\mathrm{AE})=\mathrm{MP} / \mathrm{Pi}$, where $\mathrm{Pi}=$ marginal cost of the $\mathrm{i}^{\text {th }}$ input. Since rural farmers are price takers in the input market, the marginal cost of inputi approximates the price of the factor $\mathrm{i}, \mathrm{P}_{\mathrm{xi}}$. As a result of the above computation we can to conclude the following points. If $\mathrm{MPi}>\mathrm{P}_{\mathrm{xi}}$, the input is underused and farm profit can be improved by increasing the use of this input. Conversely, if $\mathrm{MP}<\mathrm{P}_{x i}$, the input is over used and to raise farm profits its use should bereduced. The point of allocative efficiency (maximum profit) is reached when $\mathrm{MP}_{i}=\mathrm{P}_{x i}$.

\section{Economic efficiency model}

The economic efficiency level of farmers can be obtained by multiplying its respective technical and allocative efficiency levels.

\section{A Tobit regression Model specification}

According to Hosmer et al. (2000) the two limit tobit regression model is binomial that refers to the instance in which the observed outcome can have only two possible types (e.g. "yes" vs. "no"). Regularly, the outcome is coded as " 0 " and " 1 " in binary Tobit regression as it leads to the most straight forward interpretation. The target group (referred to as a "case") is usually coded as " 1 " and the reference group (referred to as a "non-case") as "0". The Specification of a two limit tobit Regression Model for this study is constructed to show the relationship between inefficiency index with farm and farm head related attributes as follow: 


$$
\text { Eind }=\beta_{0}+\beta_{1} \text { gen }+\beta_{2} \text { age }+\beta_{3} e d u+\beta_{4} h f \text { size }+\beta_{5} c o p+\beta_{6} \text { tpseed }+\beta_{7} f r q l+\beta_{8} m d s e e d+\beta_{9} r f s i z e+\beta_{10} l o w n+\varepsilon_{i},(\mathbf{4})
$$

Variable Description, measurement and Tobit regression mode

Efficiency indices (Eindx):are the dependent variable which represents the technical, allocative and economic efficiency scores of an individual crop produced rural farmer or farm of Abeshigewpreda or district. The efficiency level of the rural farmers was obtained from the calculation of frontier production function. The description of independent variables expected to influence the dependent variable are listed below here and if the respective parameters signs of variable is positive it can be to conclude as it has a positive effect on production efficiency where as if it is negative implies that it has a negative impact on production efficiency.

Gender of household head (gen): Gender is a binary variable where $1=$ male and $0=$ female, that is included to estimate the impact of gender on technical efficiency level of farmers. Female headed household would have better opportunity to carry out frequent follow up and supervisions of the rural farm activity on their plot.

The house hold head age (age): Age is defined as the age of the respondent that measured by years and is also considered as the experience of the farmers in primary decision making in the farming operation or the number of years the farmers have being involved in crop farming. As different literatures have shown, negative coefficient is expected to inefficiency effect.

Household's family size (hfsize): Household Size measures the number of people (adult men and women and children) who were living with the rural farmer during the 2010/2011 spring (belg) cropping season. The expected sign for household size is positive.

Education (edu):Education is a continuous variable measured by the number of years spent in school. Education as a human capital variable is a relevant factor in technology adoption. Educated farmers easily adopt improved farming technology and therefore should have higher efficiency scores than farmers with low level of education (Seyoumet al., 1998). Educated farmers are expected to acquire, analyze and evaluate information on different inputs, outputs and market opportunities much faster than illiterate farmers. The expected impact of education on efficiency is positive.

Cooperative membership of rural farmer (COP):The effect of this variable is captured by the existence the farmer whether he is a member of a seed multiplication and a multipurpose cooperatives or not and it is a binary. If a farmer is a member of a cooperative, he will be the more efficient, thus, positive coefficient is expected.

Types of seed used (tpseed):Improved Seed was a measure of the amount of crops seeds in kilograms $(\mathrm{kg})$ used in 2010/2011 spring or (locally Belg) cropping season. This is a dummy variable and takes a value of 1 if a farmer uses improved seed and 0 otherwise. Improved seeds are associated with high productivity level and better capacity to resist diseases (Abay, 2007). Therefore, use of improved seed is expected to have positive effect on haricot bean output surplus.

Frequency of land plough for crop (frql):The effect of this variable would be examined the land preparation of a farmer measured by a number of land plough activities before sowing of seed. It is expected to have a positive influence on technical efficiency.

Method of crop seeding (mdseed):It is binary variable having value of 1 if household applied a row planting, and 0 , for broadcasting. The effect on the production of farmer being involved in a row planting is easier to carry out agronomic management practicesand It gives more yield and hence positively complement farm activities.

Rural Farm land Size (rfsize):Farm size is the area of land in hectares of haricot bean cultivated. The variable was used to investigate its influence on output. During the survey, the dataon size of land was collected interms of hectare. Basically, land is the main factor of production and thus positive coefficient is expected.

Land ownership status of the rural farmer (lown): This refers to the farm land ownership status of the house hold measured from 1 to 4 if the farm land is its own= 1 , if the farm land is rental $=2$, if the farm land is share cropping $=3$, for any other type $=4$. If the farm land is owned by the house hold, farmer's efficiency will be expected to increase. Thus, the sign of this variable is expected to be positive.

\section{RESULT AND DISCUSSION}

Empirical results of the study

The main purpose of this study is to assess determines the level of crop output efficiency which was produced by abeshigeworeda or district and the related influencing factors of crops production. The production of individual farm was characterized by Cob-Douglas production function. 
4.1 Results from Cobb Douglas production function

The concern of this production function model is mainly to determine the level of crops production yield which was attained by producers in the study area and also to identify the influencing factors in each output level. The variables that used in the production function were presented below here and it indicated the average yield of the survey was $1135.039 \mathrm{Kg} / \mathrm{ha}$ with the minimum amount of 333.33 $\mathrm{Kg} / \mathrm{ha}$ and maximum amount of $2400 \mathrm{~kg} / \mathrm{ha}$.

Table.2: Summary of variables used in crops production function

\begin{tabular}{lccccc}
\hline Variable & Units & Means & Std. Dev & Min & Max \\
\hline Yield & $\mathrm{kg} / \mathrm{ha}$ & 1135.04 & 437.50 & 333.3 & 2400 \\
Seed & $\mathrm{kg} / \mathrm{ha}$ & 68.60 & 24.05 & 30 & 120 \\
Fertilizer & $\mathrm{kg} / \mathrm{ha}$ & 58.02 & 51.17 & 0 & 200 \\
& & & & & 200 \\
Labor & Man day/ha & 9.7 & 4.09 & 1.33 &
\end{tabular}

\section{Source: Primary data (2010/2011 spring (locally belg) cropping season)}

Based on the above statically variables, the maximum likelihood estimation (MLE) of the production parameter of crops producers of Abeshigeworeda or district in guraze zone are presented as follows.

Table.3:The MLE of the Cobb-Douglas stochastic frontier production Function

\begin{tabular}{ccccc}
\hline $\begin{array}{c}\text { Variables } \\
\text { (Output) }\end{array}$ & Parameter & $\begin{array}{c}\text { MLE } \\
\text { Coefficient }\end{array}$ & Std. Error & Z-Statistics \\
\hline Constant & $\beta 0$ & $5.120^{* * *}$ & 0.3920 & 13.06 \\
Fertilizer & $\beta 1$ & $0.3061^{* * *}$ & 0.0604 & 5.07 \\
Seed & $\beta 2$ & $0.1919 * *$ & 0.0942 & 2.04 \\
Labor & $\beta 3$ & $0.1141^{* * *}$ & 0.0548 & 2.08 \\
Wald chi-square & & & $48.24(0.000)^{* * *}$ & \\
Model Variance & & & 0.0994 & 0.6076 \\
Gamma & & -35.807997 &
\end{tabular}

Source:- survey data 2010/2011 spring (locallybelg) cropping season

All the three coefficients have positively influenced crops production and also they were statically significant at $5 \%$ and $1 \%$ levels. This implies that as each of these variables is increased and the other factors affecting are remaining constant, the output of crops will be increased. The coefficient that representing the volume of fertilizers which was used by producers has a positive sign and revealed $1 \%$ level of significance relationship with production outputs. This implies that a percentage increment on the volume of fertilizers can increases the volume of crops output by 0.31 percent. This result is supported by the findings of Tewodros (2015).
The coefficient of seed was found to be positive and statistically significant at 5\% level. The implication of this result is a percent change in the volume of seed used by the farmers can increased the yield of crops by 0.19 percent. In the contrary of this result, the study result conducted by Tamirat (2017) revealed that seed has negative and insignificant impacts on crops yields. The other variable coefficient is labor and it was estimated with a positive and significant at 5\% level. This result showed that the output can be increased by 0.11 percent with a percentage increase in labor. The result is consistent with the findings of Tewodros (2015) and Tamirat (2017) which found the similar results that labor has positive and significant influences on crops yields. 
Since results of the walid chi-square statics is 48.24 with p-value 0.000 and at $1 \%$ significant level, it can be to conclude that there is inefficiency in production of crops production with in the study area. The coefficient score of sigma is about 0.6076 this implies that the proportion of variation in the model is as a result of technical efficiency. As the score indicated about $60.8 \%$ of the variation in crops output was as a result of the differences in technical efficiency. In other words about 61 percent of the variation with in the error term was due to the inefficiency component. Based on this information it can be to conclude that about $39 \%$ of the variation was due to random shocks that cannot be controlled by rural farmers. Therefore, if it can to minimize the gap of technical inefficiencies between producers there is the opportunity to maximize the crops out puts with in the study area.

\subsection{Efficiency analysis}

The technical, allocative and economic efficiency of crops farms were estimated to develop holistic analysis of then existing farm's performance with in the study area.

\subsubsection{Technical Efficiency Analysis}

The results of this study showed that technical efficiency of the farmers ranging from 19.95 percent to 95.17 percent with a mean value of 64.69 percent. The implication of this result is that the best performing producer attained at 95.17 percent efficiency while the least performing farmer achieved about $19.95 \%$ efficiency level.

\subsubsection{Allocative Efficiency analysis}

The allocative efficiency score of crops producer rural famers with in the study area is ranging from 15.52 to $97.69 \%$ with an average score of $57.47 \%$. This result revealed that crops producing rural farmers have the room to increase their allocative efficiency level by $42.53 \%$ if production constraints are solved.

\subsubsection{Economic Efficiency analysis}

Table. 3 below here indicated also the economic efficiency score of crops producing rural farmers of Abeshigeworeda or district in gurage zone. These efficiency scores has gotten from the combination effect of the technical and alloctive efficiency factors. As the result of the study revealed, the average economic efficiency of the farmers in the study area is about $35.94 \%$ whereas the scores ranging from the lower value $10.9 \%$ up to the maximum value of $81.29 \%$. When we are comparing the EE against the TE of the study, it is clearly observable that the TE is higher than the EE. The important point to realize here is providing a great attention to maximize the EE of rural farmer crops producers in the study area.

Table .4: Frequency Distribution of Technical (TE), Allocative (AE) and Economic (EE) of crops producing rural farmers.

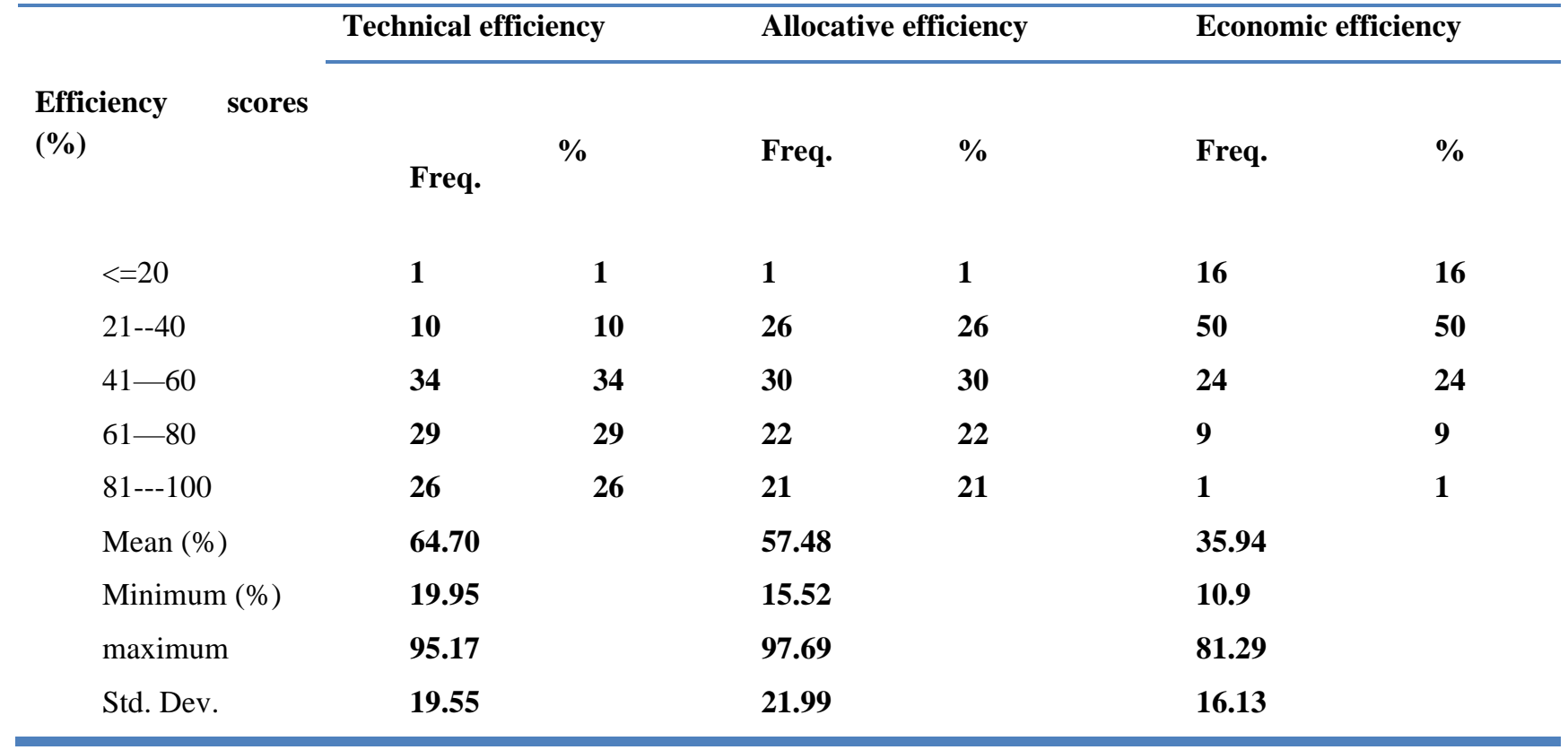

Source:- survey data 2010/2011 spring (locally belg) cropping season

Based on the frequency distribution indicated in the above table 4 , the highest number of producers has the TE between $41 \%$ and $60 \%$ which is holding $34 \%$ of the rural farmers under the study. Regarding to $\mathrm{AE}$ the greater number of farmers achieved the AE between $41 \%$ and 60 which representing $30 \%$ of total respondents. Lastly, the 
EE scores of producers is higher with in the group between $21 \%$ and $40 \%$ achieved group which comprises $50 \%$ of the total producers.

Factor affecting efficiency in crops producer in the study area

Based on the estimated parameter resulted from Tobit regression model, the influencing factors impact on production and their respective signs were identified. The positive or negative signs indicated the effects of each explanatory variable on the scores of TE, AE and EE of production. Therefore those variables with a higher impact value should be given an attention in order to improve the existing efficiency level of crops production in Abeshigeworeda or district and results of the variables are presented below here.

Gender:of the farmer showed that female crop producers have a negative relationship with TE but a positive relationship with AE and EE. Therefor based on the result, it can be to conclude being a male has higher TE has ability reduced inefficiency but lower AE and EE. This study result is agreed with the findings bakery et al (2015).

Household family size: the result coefficients of the TE for showed a negative and insignificant relationship. But the estimated coefficients for the allocative and economic efficiency groups for the variable showed a positive relationship with the independent variable and it was statistically significant at 5\% level. This result is similar with the findings of Essa (2011) that economic inefficiency was positively and significantly affected by family size but showed variation on the results of TE.

As the estimated coefficients result for education level of the farm head indicated, it has a positive relationship with TE and EE but negative relationship with AE of a farmer. This finding showed a compliance with the findings Tamirat(2017) and Tewodros (2015). As education is a fundamentals tool for crop production and development there might be knowledge and skill ignorance by some farm house holds or the farm households missed the application of their knowledge and skills of production. This might be one of the reasons for the existence of poor resource allocation during the haricot bean crop production.

The estimated coefficient for membership in cooperative revealed a positive relationship with EE of the farmers. Farm heads that had joined cooperative institutions showed a tendency of increasing efficiency against nonmembers in crop production. This happening is as a result of providing the cooperative institutions particularly different service like timely input supply, mechanization, credit, storage and technical training services to their individual members which might be the sources of motivation of the small scale crop producers in Abeshigeworeda or district. Similar result was found by Bakary and et al.(2014).

The estimated coefficient of land size is directly related with all the three categories of efficiencies at a significant level of $1 \%$. As the size of land increases, motivation of the farmers in the study area also increased in turn enable to increase all the three efficiency categories. This has an agreement with the study's results conductedBakaryet al.(2014) who found land size have a positive and significant influence on outputs.

Though significant, all the three estimated coefficients of land ownership status indicated a negative relationship with all three efficiency categories and the AE and EE are significant at $1 \%$ level of significance. Regarding to this variable, there were different dummy variables which the above results were bases upon. The results were obtained by performing each dummy variable against the remaining counterparts. If we assigned 1 for owned land status, then all the remaining three dummy variables take 0 and the like. The above result interpretation is that land owned farm heads were less efficient technically, allocatively and economically when they compared to those farmers who didn't have their owned lands.

Table.5: The estimated TE, AE and EE results of Tobit regression model

\begin{tabular}{lrrrrrr}
\hline \multirow{2}{*}{ variable } & \multicolumn{2}{c}{ Technical Efficiency } & \multicolumn{2}{c}{ Allocative Efficiency } & \multicolumn{2}{c}{ Economic Efficiency } \\
\cline { 2 - 7 } constant & coefficient & Std, Error & coefficient & Std, Error & coefficient & Std, Error \\
gender & 0.4556 & 0.1130 & 0.4889 & 0.1230 & 0.2320 & 0.0895 \\
age & -0.009 & 0.0336 & 0.0642 & 0.0366 & 0.0355 & 0.0266 \\
Household size & 0.0035 & 0.0022 & -0.004 & 0.0024 & -0.008 & 0.0017 \\
Education level & -0.006 & 0.0073 & 0.0251 & 0.0080 & 0.0120 & 0.0058 \\
Coop membership & 0.0082 & 0.0046 & -0.006 & 0.0049 & 0.0002 & 0.0036 \\
& 0.0350 & 0.0382 & 0.1037 & 0.0416 & 0.0634 & 0.0302 \\
\hline
\end{tabular}




\begin{tabular}{rllllll} 
Types of seed & 0.1090 & 0.330 & -0.154 & 0.0360 & -0.028 & 0.0262 \\
Freq of land ploug & 0.0123 & 0.0240 & 0.0044 & 0.0259 & 0.0125 & 0.0188 \\
Method of seeding & 0.2331 & 0.0367 & -0.054 & 0.0399 & 0.0999 & 0.0290 \\
Land size & -0.279 & 0.0854 & 0.7408 & 0.0929 & 0.3284 & 0.0676 \\
Land Ownership & -0.043 & 0.0625 & -0.167 & 0.0680 & -0.173 & 0.0495 \\
\hline
\end{tabular}

Source: survey data 2010/2011spring (locallybelg) cropping season

\section{CONCLUSION AND RECOMMENDATION}

The results of this study showed that technical efficiency of the farmers ranging from 19.95 percent to 95.17 percent with a mean value of 64.69 percent. The implication of this result is that the best performing producer attained at 95.17 percent efficiency while the least performing rural farmer achieved about $19.95 \%$ efficiency level. The allocative efficiency score of crop producer farmers with in the study area is ranging from 15.52 to $97.69 \%$ with an average score of $57.47 \%$. This result revealed that crop producing farmers have the room to increase their allocative efficiency level by $42.53 \%$ if production constraints are solved. As the result of the study revealed, the average economic efficiency of the farmers in the study area is about $35.94 \%$ whereas the scores ranging from the lower value $10.9 \%$ up to the maximum value of $81.29 \%$. Regarding to the yield of crops per hectare of land is ranging from $3.33 \mathrm{q} / \mathrm{ha}$ and $24 \mathrm{q} / \mathrm{ha}$ with a mean yield amount is $11.35 \mathrm{q} / \mathrm{ha}$.

From Tobit regression model, among the socio economics attributes of farmer and farms, particularly for method of seeding and farmers applying line sowing are more efficient than those farmers who used broadcasting seeding method with high significant level under TE and EE. The farmers who are a member of cooperative institutions are highly efficient when they compared to non-members with the significant level under all the three efficiency categories. Respondent farmers who have the experience for a well land preparation showed higher positive relationship for the entire three efficiency category. Farmers who plough their land more than three times before sowing were more efficient when compared to those farmers who plough less than 3 times. Based on the above obtained the three categorical mean efficiency level of crop producing farmers with in the study area, the farmers were not operating at maximum level of production.

Based on the above findings of the study the proposed recommendations are provided below here.
I. As the results of the study indicated, among the basic production inputs the application of fertilizer and improved seed have shown a positive impact on efficiency though the farmers used under the recommended dose. Therefore the zonal and woreda level agricultural bureaus should promote strongly to change the existing under dose application and also the rejection of inputs completely. Not only can the recommended rate of inputs increase the output of the crop but also increasing the number of technology adopting farmers.

II. Since membership in cooperative institution particularly in seed production and marketing cooperatives has shown a positive impact on crops production efficiency, therefore the formation of similar institution and also bringing nonmember farmers to membership is must be a strategy to enabling farmers to use a modern agricultural production services like timely and a better quality input access, input and output marketing, credit services, mechanization and storage facility services etc.

III. The other findings of this study was increasing the frequency of land plough is positively affected production efficiency. Therefore agricultural, development agents should promoting a better land preparation by farmers through increasing the number of plough 3 and more than 3 times hence it can helps greatly the efforts to increase the productivity of the crop. Promoting line sowing is also crucial against broad casting methods to increase the yield of the crop.

The above listed points are the major recommendations which drown from the finding of the study.

\section{REFERENCES}

[1] Aigner, D.J., Lovell, C.A. and Schmidt, P. (1977).Formulation and Estimation of Stochastic Frontier 
Production Function Models.Journal of Econometrics 6:2137.

[2] BakaryKaddy. Sulyman.Sanyang(2014) Evaluation of Technical, Allocative and Economic efficiency of rice producers: A Case Study in central river Region north and south of the Gambia. A Thesis of MSC in Agricultural Economics.University Of Kwame Nkrumah.

[3] Boere A., Thijs R., Daphne W., Kidane D. and Wannes D. 2015. Business Opportunities Report Oilseeds and pulses \#5 in the series written for the "Ethiopian Netherlands business event 5-6 November 2015, Rijswijk, The Netherlands".

[4] Burhan, O., Ceylan, R.F. and Hatice, K. (2009) A Review of Literature on Productive

[5] CIA.(2018) "Ethiopia." cia.gov.Central Intelligence Agency. Available from: https://www.cia.gov/library/publications/the-worldfactbook/geos/et.html.[Accessed 12 May 2018].

[6] Coelli, T.J. and Battese, G.E. (2005) An Introduction to Efficiency and Productivity Analysis, Efficiency in Agricultural Production. Journal of Applied Scienes Research, 5(7): pp 796-801.

[7] Endrias, Ayaleneh, Kassa and Eyasu(2013) Productivity and efficiency analysis of Smallholder Maize producers in southeren Ethiopia. Journal of Human Ecology, 41(1): pp 67-75.

[8] EssaChanie(2011) Economic Efficiency of smallholder major crops production in the central highlands of Ethiopia. Masters of Thesis in Agricultural and Applied Economics specialization in Agricultural Policy and Trade from University of Egerton. [Accesed 15 May 2018)

[9] FAO and WFP (2010) quoted by Solomon bizuayehu (2014), Crop and Food Security Assessment Mission to Ethiopia.[Internet]. Food and Agriculture Organization and World Food Program, May 2018].

[10] Khairo, S.A. and Battese, G.E. (2004).A Study of Technical Inefficiencies of Maize Farmers within and outside the New Agricultural Extension Program in the Harari Region of Ethiopia, Kluwer Academic Publishers, Boston.

[11] Kumbhakar, S.C. and Tsionas, E.G. (2006) quoted by Essa (2011). Estimation of Stochastic Production Functions with Input-Oriented Technical Efficiency.Journal of Econometrics 133(1): 71-96.

[12] Mersha, F.G. (2004). Analysis of Technical Efficiency of Wheat Production: A Study in MachakelWoreda, Ethiopia. Unpublished MSc Thesis, Alemaya University.

[13] Mulugeta, A., Tesfaye, K. and Dagne, K. 2015. The Importance of Legumes in the Ethiopian Farming System

[14] Omonona, B.T., Egbetokun, O.A. and Akanbi, A.T. (2010) quoted by Essa (2011). Farmers Resource - Use and Technical Efficiency in Cowpea Production in Nigeria.Economic Analysis and Policy 40 (1): 87-95.

[15] Seyoum, A., Dorosh, P. and Sinafikeh, A. (2011) Crop Production in Ethiopia: Regional Patterns and Trends. Ethiopia Strategy Support Program (ESSP), February 2018].
[16] Tamirat, G., Tewodros, T., and Deribe K. (2017). Determinants and Resource Use Efficiency of Haricot Bean Production in Halaba Special District, Southern Ethiopia.Journal of Economics and Sustainable Development8(17): pp 12-18.

[17] Tewodros, T. 2014. Determinants of Smallholder Pulse Producers Market Orientation in Southern Ethiopia, Asian Journal of Business Management.6(2): 101-103 